\title{
The Role of Cytokine Interleukin-2, Transcription Factor of FoxP3 in the Immunological Regulation of Allergic Rhinitis
}

\author{
Bambang Suprayogi Resi Utomo', Mochammad Hatta², Robert H. Sirait ${ }^{3}$, Sutji Pratiwi4, \\ Muhammad Nasrum Massi ${ }^{5}$
}

\footnotetext{
${ }^{1}$ Department of Ear Nose and Throat, Faculty of Medicine, Indonesia Christian University of Jakarta, Jakarta, Indonesia

${ }^{2}$ Molecular Biology and Immunology Laboratory for Infection Diseases, Faculty of Medicine, University of Hasanuddin, Makassar, Indonesia

${ }^{3}$ Department of Anesthesiology, Faculty of Medicine, Indonesia Christian University of Jakarta, Jakarta, Indonesia ${ }^{4}$ Department of Ear Nose and Throat, Faculty of Medicine, University of Hasanuddin, Makassar, Indonesia ${ }^{5}$ Department of Microbiology, Faculty of Medicine, University of Hasanuddin, Makassar, Indonesia

Email:hattaram@yahoo.com
}

How to cite this paper: Utomo, B.S.R. Hatta, M., Sirait, R.H., Pratiwi, S. and Massi, M.N. (2018) The Role of Cytokine Interleukin-2, Transcription Factor of FoxP3 in the Immunological Regulation of Allergic Rhinitis. International Journal of Otolaryngology and Head \& Neck Surgery, 7, 7-19.

https://doi.org/10.4236/ijohns.2018.71002

Received: November 25, 2017

Accepted: January 27, 2018

Published: January 30, 2018

Copyright (C) 2018 by authors and Scientific Research Publishing Inc. This work is licensed under the Creative Commons Attribution International License (CC BY 4.0).

http://creativecommons.org/licenses/by/4.0/

\begin{abstract}
Allergic rhinitis (AR) is the inflammation of nasal mucosa due to the type 1 hypersensitivity reactions mediated by immunoglobulin $\mathrm{E}$ (IgE) and triggered by certain allergens. The latest concept in allergic disease is the role of regulatory $\mathrm{T}$ cells (Treg). Interleukin-2 enhances the function and survival of Treg to perform its function as a controller of effector for forming a tolerant system by suppressing and regulating the homeostasis system. Treg has a transcription factor FoxP3 which plays a role in developing major function of Treg and progression to produce IL-10 and TGF- $\beta$. The atopic diseases are caused by a deficiency of Treg. The new perspective is low-dose IL-2 therapy towards autoimmune disease and allergic inflammation. Low-dose IL-2 therapy requires further clinical studies to optimize the dose, time, and the schedule of the IL-2 treatment. FoxP3 has the potential to assist in evaluating the active process of immunological process, which cannot be evaluated by Th1 and Th2 markers, and FoxP3 can be a successful immunotherapy marker.
\end{abstract}

\section{Keywords}

Allergic Rhinitis, Interleukin-2, FoxP3

\section{Introduction}

Allergic rhinitis (AR) is an inflammatory disease caused by allergic reactions in 
atopic patients which previously sensitized at the same allergen, and the release of a chemical mediator in the event of re-exposure with specific allergens [1]. AR symptoms are itchy nose, sneezing, nasal congestion, and rhinorrhea after exposed by allergens mediated by immunoglobulin E (IgE) [2] .

Allergic rhinitis develops from environment, immunologic and genetic roles [3]. Allergic rhinitis is not a dangerous disease, but its symptoms can affect a quality of life [4]. Allergic rhinitis is an unusual disease for people with the age of below 5 years old [5], with the peak incidence occurred between 17 and 22 years old [6] [7]. The impacts of allergies on the economy are increasing as well. Between 2000 and 2005, the cost of treating AR almost doubled from $\$ 6.1$ billion to $\$ 11.2$ billion, with more than a half of the money spent on prescription medications [8]. The costs that related to the lost productivity, the missed of jobs, and also health care costs incurred by exacerbation of coexisting medical conditions which caused by allergy are more difficult to quantify [9]

Immunological understanding is important in understanding the pathophysiology, diagnosis, and treatment of the disease. Allergic rhinitis is a disease with symptoms that comes from immunologic abnormalities [1]. The theory of Immunology in AR disease continues to grow. At first, it related to the understanding of the role of Th1 and Th2, afterwards the latest concept of allergic disease continues to the role of regulatory $\mathrm{T}$ cells (Treg). Treg produced cytokines interleukin-10 (IL-10) and Transforming Growth Factor- $\beta$ (TGF- $\beta$ ) [10]. IL-10 and TGF- $\beta$ play a role in suppressing specific immune responses Th1 and T2 [11]. Treg reflecting the transcription of forkheadbox factor (FoxP3) that contributes to the development and function of Treg. Treg in its function and survival requires the interleukin-2 (IL-2) [12].

This paper will discuss the role of IL-2 and FoxP3 that affect the pathogenesis of AR. The purpose of this paper is to describe the role of cytokines so that can be considered as the therapy or a sign of the success of the therapy.

\section{Discussion}

\subsection{Pathogenesis of Allergic Rhinitis}

Allergic reaction is an inflammatory disease begins with the stage of sensitization and the followed by allergic reactions [13]. Allergic reactions consist of two phases; first, the rapid allergic reaction, it starts from the contact with the allergens that lasts up to 1 hour thereafter; second, the slow-phase allergic reaction, lasts for 2 - 4 hours with the peak of 6 - 8 hours (hyperreactivity phase) after exposed by the allergens, it may last up to 24 - 48 hours [14]. The pathogenesis of $\mathrm{AR}$ is divided into sensitization and elicitation phases that can be distinguished over the activation and effector stage [15].

\subsubsection{Sensitization Phase}

All human nasal mucosa exposed by various particles such as pollen, dust, animal skin flakes and other proteins inhaled with hot air. Macrophages or monocytes acts as an Antigen Presenting Cells (APCs), will process allergens and 
present some peptides from allergens on the major histocompatibility complex (MHC) class II molecule. APC will migrate to adenoid, tonsils or lymph nodes which are then presented on Th0 cells [14].

The atopic patients have T cells receptor (TCR) in the Th0 lymphocytes, with $\mathrm{CD} 4$ molecules that can recognize the peptides presented by the APCs. The simultaneous contacts happened between TCR and CD4 molecules with MHC class II molecule, CD28 and B7, and the accessory molecules in T cells with ligand in the APCs triggered a series of activities in cell membranes, cytoplasmic and nuclei of $\mathrm{T}$ cells resulting in the production of cytokines. The releases of APCs towards cytokines such as IL- 1 will activate Th0 to proliferate into Th1 and Th2. Th2 produces various cytokines such as IL-3, IL-4, IL-5, and IL-13 [14] [15].

The continues low-dose allergen exposure in atopic patient and allergen presentation by APCs cells to B cells is accompanied by the effect of IL- 4 and IL-13 cytokines followed by their receptor on the surface of B lymphocytes, then stimulates B lymphocyte cells to become active and will produce an increasing amount of IgE. The IgE's production is spread freely in the circulation, and some of them bind to its receptor with high affinity on the surface of basophils and mast cells. Mast cells then enter the post-capillary of venous in the mucosa which then leaves the circulation and enter the tissues including the mucosa and sub-mucosa of the nasal. In such conditions, a person can be referred as a sensitive or sensitized person, in which gives a positive result on the skin test [14] [15].

\subsubsection{Elicitation Phase}

The first stage of the elicitation phase is the activation stage. At the activation stage, sensitized patient in which in the condition of re-exposure with an allergen similar to the previous exposure to the nasal mucosa, there may be a bond between two adjacent IgE molecules on the surface of the mast or basophil cell with the cross-linking allergen. The interaction between $\operatorname{IgE}$ that related to the surface of mast cells or basophils (with these same allergens) triggers the activation of guanosine triphosphate (GTP) binding (G) protein which activates phospholipase $\mathrm{C}$ enzyme to catalyze phosphatidylinositol biphosphate (PIP2) into inositol triphosphate (IP3) and diacylglycerol (DAG) on PIP2 membrane. Inositol triphosphate causes the release of calcium intra-cell $\left(\mathrm{Ca}^{2+}\right)$ ions from the endoplasmic reticulum. Calcium ions in the cytoplasm activate several enzymes such as phospholipase-A and Calcium-calmodulin complex that activate the myosin light chain kinase enzyme. Furthermore, Calcium ions and DAG together with the phospholipid membrane activate the protein kinase $\mathrm{C}$. As a result of this activity, the formation of lipid mediators belonging to newly formed mediators such as prostaglandin D2 (PGD2), leukotriene C4 (LTC-4), platelet activating factor (PAP) and exocytosis of mast cell granules containing chemical mediators known as preformed mediators histamine, tryptase and bradykinin [14] [15].

Histamine is an important chemical mediator that is released by mast cells 
because histamine can lead to more than $50 \%$ of allergic reaction symptoms of the nose (sneezing, rhinorrhea, itchy nose and stuffy nose). Histamine has a direct effect on the endothelium that increases capillary permeability that causes a transudation process that will aggravate the symptoms of rhinorrhea. Histamine bonding to nociceptic type $\mathrm{C}$ receptors in the nasal mucosa derived from Trigeminal nerve causes itching in the nose and stimulates the onset of sneezing. The effect of histamine on the gland (due to parasympathetic reflex activation) has the effect of increasing gland secretion causing serous rhinorrhea symptoms. Furthermore, histamine also causes symptoms of nasal congestion it causes vasodilation of blood vessels, transudation to the interstitial resulting nasal mucosa and especially edema turbinate. Symptoms that immediately arise after the exposure to allergens are called fast phase reactions or immediate phase reactions. Released histamine from mast cells will be metabolized by histamine N-methyl transferase (HMT) in both epithelial and endothelial cells [14] [15].

The second stage of the elicitation phase is the effector stage. In the effector stage, the release of cytokine and endothelial activation give a result in slow phase reaction soon after the immediate phase. Slow-phase reactions occur in some patients $(30 \%-35 \%)$ of allergic rhinitis that occurred between $4-6$ hours after the allergen exposure and persisting for $24-48$ hours. Slow-phase reactions is the occurrence of various kinds of inflammatory cells, especially eosinophil cells as major effector cells in chronic allergic reactions such as allergic rhinitis and bronchial asthma. Eosinophil cells in the movement of blood circulation to tissue or location of allergies influenced by chemotactic factors, through several stages such as the migration of the eosinophil cells from the middle to the edge of the blood vessel wall and begin to reversible bend with endothelial inflammation (rolling), followed by attachment to blood vessel walls mediated by the interaction of endothelial adhesion molecules such as inter cell adhesion molecule-1 (ICAM-1) and vascular cell adhesion molecule-1 (VCAM-1) that are specific to the attachment of eosinophil cells because the eosinophil cells express VLA- 4 to be administered with VCAM-1. ICAM-1 is also expressed by the nasal mucosal epithelial cells patients with allergic rhinitis who get specific persistent allergen exposure and become the basic concept of minimal persistent inflammation (MPI) seen in allergic rhinitis to house dust mites (HDM) in symptom-free [15] [16]. Eosinophil was first reported by Paul Ehrlich (1879) on the basis of specific behavior toward painting. The role of eosinophil as pro-inflammatory in chronic allergic disease is the subject of basic research in therapy. Eosinophil in the form of progenitors is derived from the bone marrow, and then the peripheral blood is found in the nasal mucosa of allergic rhinitis patients. Eosinophil in peripheral blood is found in small blood cells (1\%) and has a short half-life (8 - 18 hours). In the nasal mucosa of allergic rhinitis patients, eosinophil cells play the important role in the pathophysiological changes of allergic rhinitis. This because the content of various chemical mediators such as major basic protein (MBP), eosinophil cationic protein (ECP), eosinophil derived neurotoxin (EDN) and eosinophil peroxidase (EPO) which have the effect of disaggregation and 
desquamation of the epithelium, cell death, mucosal and mucosal inactivation cell damage due to free radicals [15] [16]. The pathogenesis of Allergic rhinitis can be seen in Figure 1.

\subsection{Immunological Role in AR}

Immunologic role in AR is about Th1 and Th2 cells balances. Most individuals do not trigger a strong response of Th2 cells to environmental antigens. In atopic patients, a strong response to Th2 that produces cytokines interleukin-4 (IL-4) and interleukin-13 (IL-13) stimulates B lymphocytes to transform into plasma cells that then produce IgE [14] [15]. Thus, the basis of AR treatment is aimed at altering the direction of the $\mathrm{T}$ cell response apart from the Th2 dominance or the loose antibody response of IgE by triggering tolerance to $\mathrm{T}$ cells against specific allergens or stimulating Treg [12]. The concept of immune response is influenced by the balance between activation receptors and inhibition for all lymphocyte populations including natural killer (NK) cells, B lymphocytes cells and $\mathrm{T}$ lymphocytes cells. In $\mathrm{T}$ cells, the best known inhibitory receptor is cytotoxic $\mathrm{T}$ lymphocyte associated antigen-4 (CTLA-4) and programmed death protein-1 (PD-1). Treg plays a role in suppressing the immune response and maintaining self-tolerance [12]. Allergic rhinitis patients with atopic history indicate Treg deficiency [17].

Treg produces an interleukin-10 (IL-10) and Transforming Growth Factor- $\beta$ (TGF- $\beta$ ) cytokine that implies an immune response, with a forkhead box

\section{Adapted from Cretios, 1998}

\section{The Early Phase}

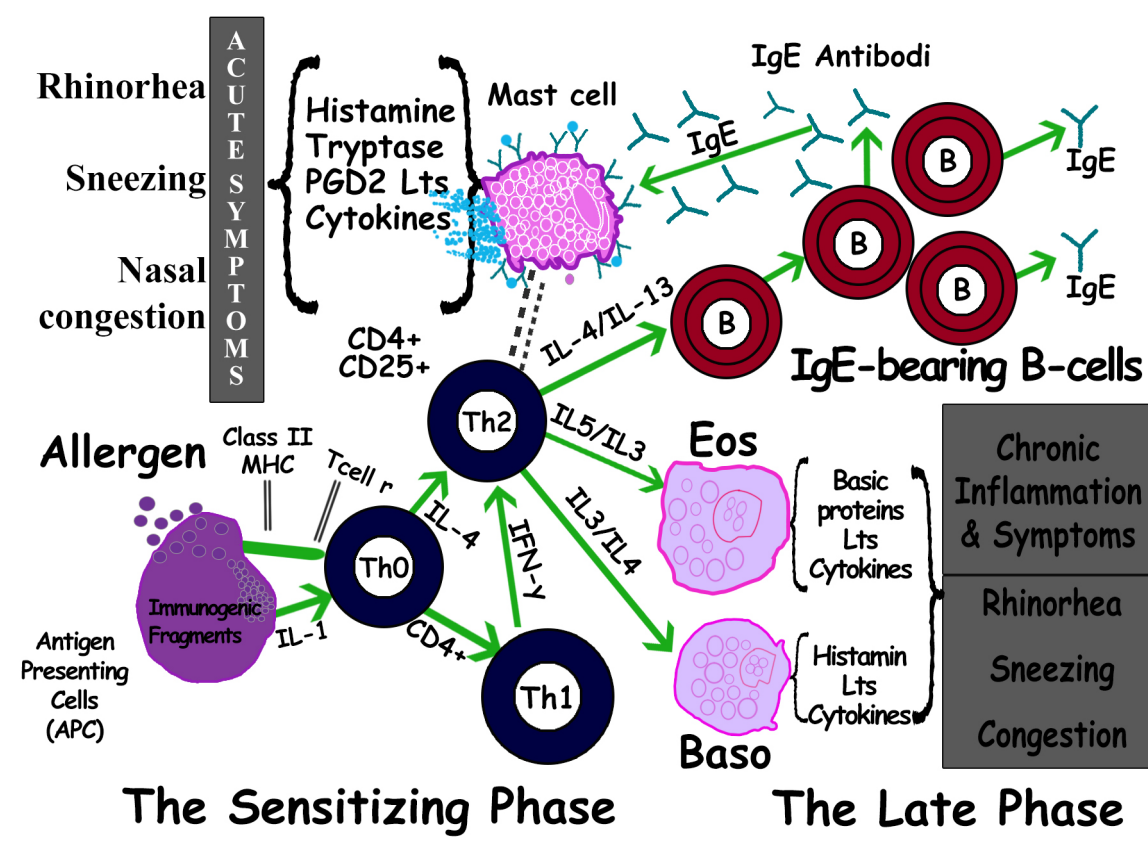

Figure 1. Pathophysiology of allergic rhinitis (Adapted from Cretios, 1998). 
transcription factor (FoxP3) that plays a role in Treg function. Treg itself in function and survival requires interleukin-2 [12].

\subsubsection{Regulator T Cell (Treg)}

Treg was originally known as suppressor $\mathrm{T}$ cells, and known as one of the subpopulation of $\mathrm{T}$ cells. Treg has a proportion of $5 \%-10 \%$ in the CD4 population in the blood circulation as well as those homing in the secondary lymphoid organs [12]. Treg morphology does not show a large difference compared to other $\mathrm{T}$ cells, but in general Treg has a size slightly smaller than other lymphocytes [18]. Treg is divided into two types namely natural regulatory $\mathrm{T}$ cells (nTreg) and induced T-cell regulator (iTreg) which acts as an immune tolerant [12].

Natural Treg (nTreg) is derived from the process of selection of immature $\mathrm{T}$ cells in the thymus organ. Immature $\mathrm{T}$ cells sustains selection in the thymus in the form of a negative selection of immature $\mathrm{T}$ cells that have $\mathrm{T}$ cell receptor (TCR) with high avidity against self-antigen with deletion or apoptosis and positive selection with receptor changes and the formation of nTreg. A small proportion of immature $\mathrm{T}$ cells with high self antigen of TCR passes the negative selection in the thymus entering the peripheral circulation. Treg subsequently played a part in suppressing the escaped portion as a tolerant immune function. Tregs derived from $\mathrm{CD}_{4}^{+}$naïve $\mathrm{T}$ cells in peripheral lymphoid organs may form after an inflammatory response and are referred to as inducible Treg (iTreg) as adaptations of antigenic exposure. iTreg is also called adaptive or peripheral Treg. Treg expresses the CD25 molecule, called $\mathrm{CD} 4^{+} \mathrm{CD} 25^{+}$Treg. The CD25 molecule is an alpha chain of IL-2 receptor that has a high affinity for IL-2, and it is owned by a majority of Treg. Treg has several other markers including expression of CTLA-4, GITR, OX40, and L-selectin (CD62L) [12]. Treg has a transcription factor called FoxP3 derived from the forkhead box transcription factor family, an important transcription factor in majority of Treg in development and function [12].

T cell lymphocyte $\mathrm{CD}^{+} \mathrm{CD} 25^{+}$that expressing FoxP3 written as $\mathrm{T}$ cells regulators FoxP3 $3^{+} \mathrm{CD}^{+} \mathrm{CD}^{2} 5^{+}$[11]. Survival and function of Treg depend on IL-2 cytokines. Interleukin-2 activates transcription factor signal transducers and activation of trancriptations-5 (STAT5), then STAT5 increases the expression of FoxP3 [12]. Activation of Treg requires Transforming Growth factor- $\beta$ (TGF- $\beta$ ) to enable the FoxP3 transcription factor for the development and function of the majority of Treg. Elimination or blockade signal of TGF- $\beta$ in T cells leads to systemic inflammatory diseases caused by un-control of leucocyte activity and reduced function of Treg [12].

Foxp3 levels in patients with symptomatic atopic were lower than those of asymptomatic atopic patients, but serum levels of IFN- $\gamma$, total IgE, and eosinophil were relatively similar [17] [19] [20]. FoxP3 expression increased significantly in patients with allergic rhinitis who received specific immunotherapy (SIT) sublingual pollen for 2 years [21]. There is a positive correlation between the increasing expression of FoxP3 and the increasing of IL-10 and TGF- $\beta$ in 
that study [21]. Measurement of FoxP3 levels has the potential to assist in evaluating the active process of immunological processes, which can't be evaluated by Th1 and Th2 markers [17] [20].

Treg undergoes the activation directly will suppress B-cell activity, inhibiting proliferation and differentiation of natural killer cells (NK). Treg produces cytokines IL-10, and TGF- $\beta$ and reduces APCs stimulation against T cells. Treg with IL-2R that has a high affinity for IL-2 leads to more consumption and reduces the need for other cells, resulting in decreased proliferation and differentiation of cells whose development requires IL-2 [12].

Treg found no difference in the amount of allergen dust mite atopic and non-atopic patients. The atopic diseases are cause only by a deficiency of Treg [17]. Treg deficiency can lead to autoimmune and inflammatory diseases [22]. In a genetic-based study, there was an association of AR with FoxP3 genetic polymorphisms in the homozygous allele [23].

\subsubsection{Interleukin-2 (IL-2)}

Interleukin- 2 is produced by $\mathrm{CD} 4^{+}, \mathrm{CD}^{+}$, activated $\mathrm{T}$ cells, dendritic cells (DC), natural killer (NK) cells and NKT cells [1]. IL-2 have monomer structure with molecular weighted $14-17 \mathrm{kD}$ and receptor (trimeric receptor); $2 \mathrm{R} \alpha \mathrm{IL}-2 \mathrm{R} \beta$ and $\gamma c[12]$.

This protein is produced by activated T cells by antigen signals, co-stimulators and cytokines. The signals continue and stimulate the transcription of the IL-2 gene through the transcription factor nuclear factor of activated T cell (NFAT). Interleukin-2 is rapidly excreted within 1 to 2 hours after the recognize antigen, peaks at approximately 8 to 12 hours and decreases within 24 hours. IL-2 production occurs in multiple signaling pathways and each channel plays an important role for the activation of multiple signaling pathways [12].

The biological activity of IL- 2 is to grow, maintain survival, and as a differentiation factor of $\mathrm{T}$ cells that play an important role in responding and controlling the immune response. Because of this, IL-2 is called the $\mathrm{T}$ cell growth factor (TCGF) [12]. The activity occurs in the cell itself that secretes IL-2 and other adjacent cells or functions can be referred to as autocrine and paracrine [12]. The survival function of IL-2 is by stimulating Bcl-2 protein which is an anti-apoptotic protein [12]. The increasing secretion of IL-2, IL-2R expression, cyclin, decreased cell cyclin inhibitors result in cell proliferation, and with multiple mechanism T-cell differentiation [12]. The function of IL-2 is maintains the survival and function of Treg to suppress the immune response. In the deficiency condition levels of IL-2 and IL-2R do to proliferation and uncontrolled T cells and $\mathrm{B}$ cells, causing autoimmune disease [12].

In a study of low-dose IL-2 therapy for chronic graft Versus host disease patients occurred the increasing level of Treg [24]. Low-dose IL-2 therapy is also used as a clinical trial concept as specific therapy activates Treg and can control autoimmune and inflammatory diseases [22]. In a genetic-based study were found an increased risk of hay fever on G homozygous alleles IL-2-330 T/G [25]. 


\subsubsection{Interleukin-10 (IL-10)}

Interleukin-10 has a heterodimer structure with a molecular weight of $20.5 \mathrm{kD}$, has an IL-10R1 receptor and an IL-10R2 complex. IL-10 is produced from populations of some activated immune cells such as dendritic cells, Th1 cells, Th2 cells, macrophages, B cells and Tregs. Because IL-10 has properties inhibiting macrophages and dendritic cells it is called negative feedback regulator [12].

The IL-10 expression is derived from the differentiation of Th naïve CD4 cells requiring receptor stimulation and inter-current transducer signals with transcriptase activators (signal transducer and activated transcriptase (STAT)) and activation of the extracellular will be activated kinase receptor (ERK) receptor pathway. Th1 cells producing IL-10 require higher doses of antigen, IL-12, and STAT-4 signalling followed by re-stimulation to maximize IL-10 expression. Th2 cells produced IL-10 require IL- 4 and STAT- 6 signals. Treg that produced IL-10 requires FoxP3 and TGF- $\beta$. Treg1 cells (Tr1) are a Treg subset that produces a lot of IL-10 and TGF- $\beta$ may decrease regulation of Th1 and Th2 responses [12] [26].

The biological activity of IL-10 inhibits the function of macrophages and dendritic cells. Interleukin-10 inhibits the production of IL-12, co-stimulator's expression and class II MHC molecules by dendritic cells and macrophages, thus inhibiting $\mathrm{T}$ cell activation and terminating immune mediated reactions. Interleukin-10 stimulates IFN- $\gamma$ that plays an important role in innate and adaptive immune reactions to intracellular microbes. Interferon- $\gamma$ also stimulates B cells to produce IgG [12].

A rare inherited autoimmune disease has been described in which mutations in the IL-10 receptor cause severe colitis that develops early in life, before 1 year of age. Knockout mice are lacking IL-10 ether in all cells or only in Treg also develop colitis, probably as a result of uncontrolled activation of lymphocyte and macrophage reacting to enteric microbes. Because of these findings, we believe that this cytokine is especially importance for controlling inflammatory reaction in mucosal tissue, particularly in gastrointestinal tract [13]. Treg also plays a role in immunotherapy by secreting IL-10 and $\operatorname{TGF} \beta$, thus stimulating $\mathrm{B}$ cells to change immunoglobulin (Ig) classes towards IgG4 and IgA in Figure 2 [1] [27]. In a genetic-based study found an association of atopic patients $68 \%$ in allele $G$ variant S138 receptor interleukin-10 [28].

\subsubsection{Transforming Growth Factor- $\beta$ (TGF- $\beta$ )}

Transforming Growth Factor- $\beta$ (TGF- $\beta$ ) is the first cytokine found in tumor cells that serve as in-vitro-tumor cell survival. Consisting of TGF- $\beta 1$, TGF- $\beta 2$ and TGF- $\beta 3$, most immune system cells synthesize TGF- $\beta 1$. TGF- $\beta 1$ is produced by Treg $\mathrm{CD} 4^{+}$, activated macrophage cells and several other cells [12].

TGF- $\beta$ is synthesized in the inactive form in Golgi complex in the form of homodimer. The mature TGF- $\beta 1$ is excreted into the extracellular by an enzymatic process which then binds to the receptor. The TGF- $\beta 1$ receptor consists of TGF- $\beta$ RI, TGF- $B$ RII with transcription factor SMAD [12]. 


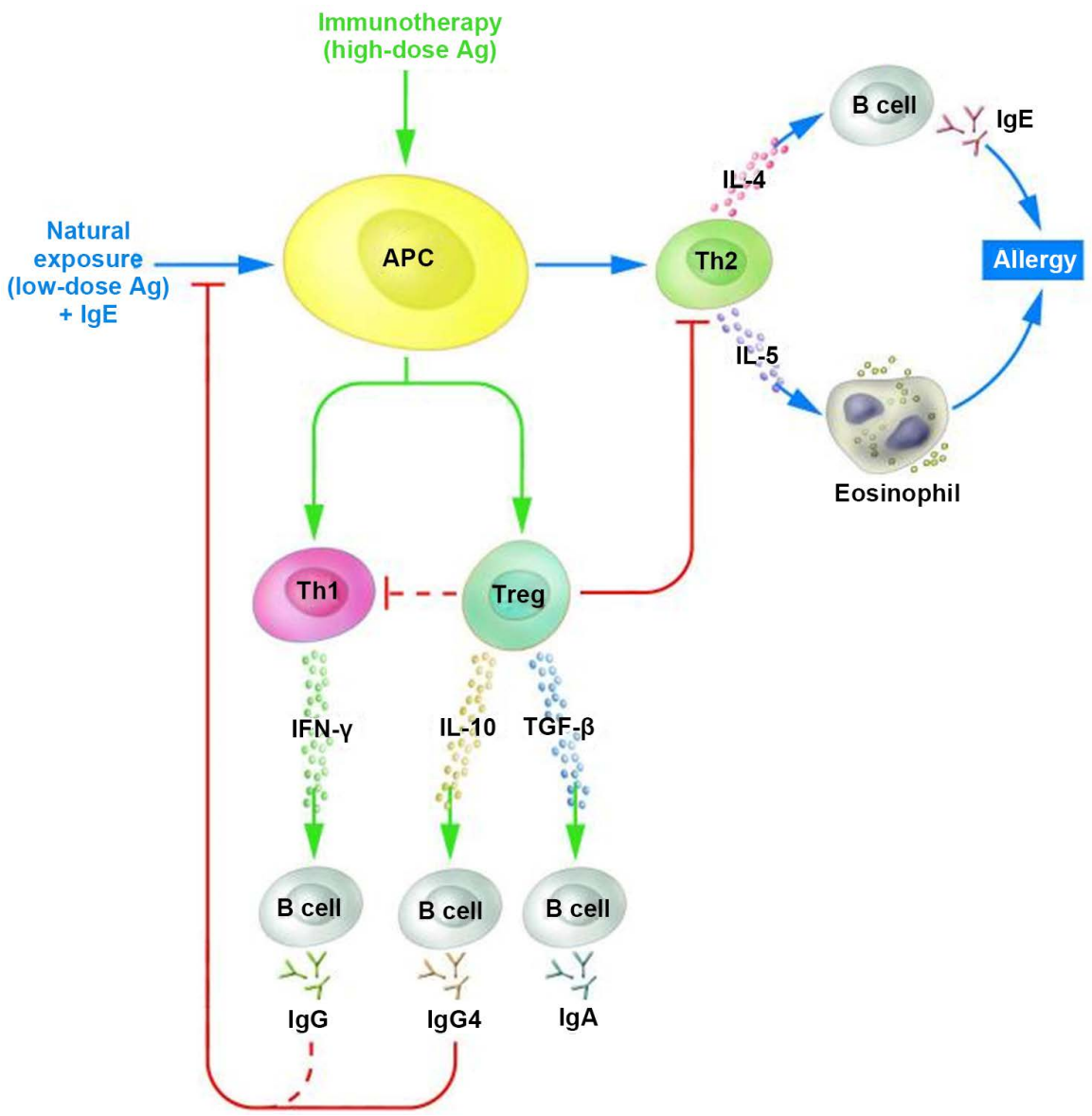

Figure 2. Potensial mechanism of conventional allergen immunotherapy. (Adapted from Robinson DS, Larche M, Durham SR, Treg and alleric disease. J Clin Invest 2004; 114: 1389-1397).

The function of TGF- $\beta 1$ is to the in-vitro Treg growth by stimulating the expression of FoxP3. In mice that have lost TGF- $\beta$ provide a picture of systemic inflammatory disease caused by uncontrolled leucocyte cell activity and lack of function of Treg [12]. TGF- $\beta 1$ inhibits macrophage activity, other cells such as neutrophils and endothelial cells, and inhibits the activity of Th1 and Th2 cells. TGF- $\beta 1$ stimulates the formation of IgA from B-cells seen in Figure 2. Immunoglobulin $\mathrm{A}$ is the antibody required for mucosal defence. TGF- $\beta 1$ improves tissue repair after local immune reactions and relieves an immune reaction [12]. In a genetic-based study found genetic variation of IL-10 and TGF- $\beta$ associated with AR susceptibility [29].

The following figure is explaining the role of interleukin-2 and FoxP3 in the pathogenesis of allergic rhinitis in Figure 3.

\section{Conclusions}

Interleukin-2 (IL-2) plays an important role in the pathogenesis of allergic rhinitis through Treg activation. Treg with IL-2R has a high affinity for IL-2, resulting in more consumption of IL-2 compared to other cells. Direct suppression results 


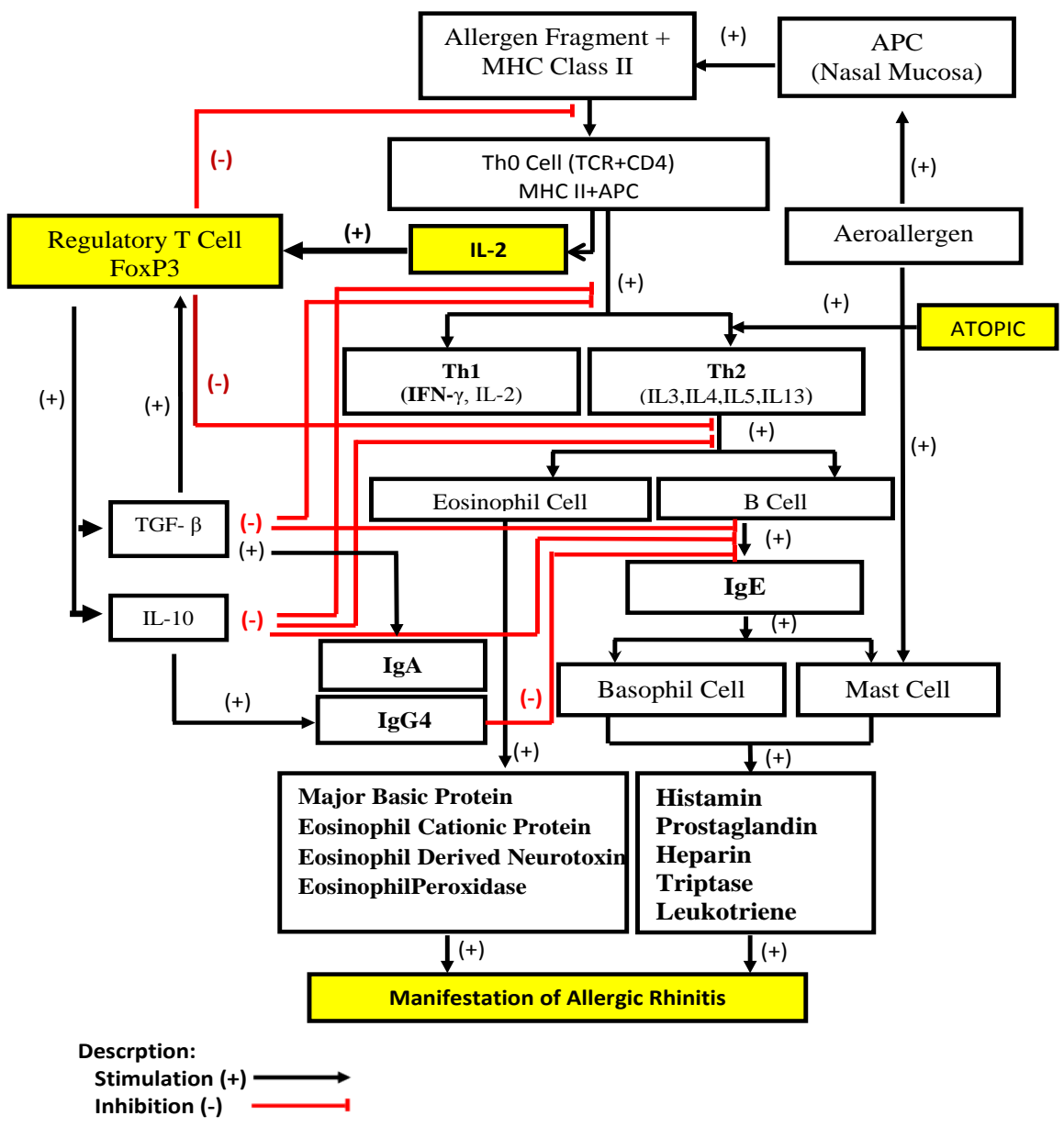

Figure 3. Schematic of conceptual framework.

from reduced supply of IL-2 in cells whose growth requires IL-2 cytokines result in decreased proliferation and differentiation of these cells. Increased levels of IL-2 will increase Treg activation. Treg activation produces IL-10 and TGF- $\beta$ cytokines that suppress the immune system. Treg has a transcription factor FoxP3 is an important transcription factor in the development and function of the majority of Treg. Rhinitis allergy occurs Treg deficiency. The increase level of IL-2 can increase the level of FoxP3, Treg, IL-10 and TGF- $\beta$ levels so as to maintain the balance of Th1 and Th2.

Treatment of allergic rhinitis is based on Allergic Rhinitis and its Impact on Asthma (ARIA) 2008 [2]. Severe AR is an indication of immunotherapy [2]. Immunotherapy can produce tolerance to allergens with various mechanisms. Several studies of immunotherapy noted a shift in the profile of cytokines that produced Th2 to Th1 by producing IL-10 both local and systemic, and proving locally elevated only in the nose [30] [31] [32]. Tolerance occurs as a result of an increase from a specific allergen suppressor $\mathrm{T}$ cell, and Treg after immunotherapy [33]. A new perspective of the therapeutic approach focuses on administering IL-2 to inflamed tissue in autoimmune and allergic-induced inflammatory cases. Low-dose IL-2 therapy in chronic graft versus host disease increased Treg 
[24]. However, low-dose IL-2 therapy requires further clinical studies to optimize the dose, time and schedule of IL-2 administration to minimize the adverse effects of IL-2 [34]. Low-dose IL-2 therapy is a clinical trial concept as specific therapy activates Treg and can control autoimmune disease and inflammation [22].

FoxP3 expression increased significantly in patients with allergic rhinitis who received specific immunotherapy (SIT) sublingual pollen for 2 years. And there is a positive correlation between the increased expression of FoxP3 on increased IL-10 and TGF- $\beta$ in the study [21]. Measurement of FoxP3 has the potential to assist in evaluating the active process of immunological processes, which can't be evaluated by Th1 and Th2 markers [17] [20]. FoxP3 can be a successful marker of immunotherapy [20].

\section{Acknowledgements}

Thank to Prof. Asadul Islam for his advice. Thanks Dr. Marwito, Dean of Medical faculty of Christian University of Indonesia. The authors thanks to Listia D. Putrianti S.E. and Arlin D. C. Oktari S. Ked for editing this manuscript.

\section{References}

[1] Chaaban, M.R. and Naclerio, R.M. (2014) Immunology and Allergy. In: Johanson, J.T., Rosen, C.A., Eds., Head and Neck Surgery-Otolaryngology, 5th Edition, Lippincott-William and Wilkins, Philadelphia, 379-406.

[2] Bausquet, J., Khaltaev, N., Cruz, A., Denburg, J., Fokkens, W.J. and Togias, A., et al. (2008) Review Rhinitis Allergy Its Inpact on Asthma (ARIA) 2008. Allergy, 86, 8-160. https://doi.org/10.1111/j.1398-9995.2007.01620.x

[3] Kauffmann, F. and Demenais, F. (2012) Gene-Environment Interactions in Asthma and Allergic Diseases: Challenges and Perspectives. Journal of Allergy and Clinical Immunology, 130, 1229-1242. https://doi.org/10.1016/j.jaci.2012.10.038

[4] Lloyd, C.M., Gonzalo, J.A., Coyle, A.J., et al. (2001) Mouse Models of Allergic Airway Disease. Advances in Immunology, 77, 163-195. https://doi.org/10.1016/S0065-2776(01)77019-8

[5] Broder, I., Higgins, M.W., Mathews, K.P., et al. (1974) Epidemiology of Asthma and Allergic Rhinitis in a Total Community, 'Tecumseh, Michigan: III. Second Survey of the Community. Journal of Allergy and Clinical Immunology, 53, 127-138. https://doi.org/10.1016/0091-6749(74)90001-3

[6] Kulig, M., Klettke, U., Wahn, V., et al. (2000) Development of Seasonal Allergic Rhinitis during the First 7 Years of Life. Journal of Allergy and Clinical Immunology, 106, 832-839. https://doi.org/10.1067/mai.2000.110098

[7] Huurre, T.M., Aro, H.M. and Jaakkola, J.J. (2004) Incidence and Prevalence of Asthma and Allergicrhinitis: A Cohort Study of Finnish Adolescents. Journal of Asthma, 41, 311-317. https://doi.org/10.1081/JAS-120026088

[8] Soni, A. (2008) Allergic Rhinitis: Trends in Use and Expenditures, 2000 to 2008. Agency for Healthcare Research and Quality 2008. Statistical Brief 204. https://meps.ahrq.gov/data_files/publications/st204/stat204.pdf

[9] Derebery, M.J. and Berliner, K.I. (2000) Allergy and Health-Related Quality of Life. Otolaryngology-Head and Neck Surgery, 123, 393-399. 
https://doi.org/10.1067/mhn.2000.109481

[10] Levings, M.K., Sangregorio, R., Galbiati, F., et al. (2001) IFN-Alpha and IL-10 Induce the Differentiation of Human Type $1 \mathrm{~T}$ Regulatory Cells. Journal of Immunology, 166, 5530-5539. https://doi.org/10.4049/jimmunol.166.9.5530

[11] Akdis, M., Verhagen, J., Taylor, A., et al. (2004) Immune Responses in Healthy and Allergic Individuals Are Characterized by a Fine Balance between Allergen-Specific $\mathrm{T}$ Regulatory 1 and $\mathrm{T}$ Helper 2cells. Journal of Experimental Medicine, 199, 1567-1575. https://doi.org/10.1084/jem.20032058

[12] Abbas, A.K., Lichtman, A.H. and Pillai, S. (2015) Cellular and Molecular Immunology. 8th Edition, Elsevier Saunders, Philadelphia, 199-337.

[13] Pearlman, D.S. (1999) Pathophysiology of the Inflammatory Response. Journal of Allergy and Clinical Immunology, 104, 132-136. https://doi.org/10.1016/S0091-6749(99)70308-8

[14] Bubnoff, D., Geiger, E. and Beiber, T. (2001) Antigen Presenting Cell in Allergy. Journal of Allergy and Clinical Immunology, 108, 329-339.

https://doi.org/10.1067/mai.2001.117457

[15] Baraniuk, J.N. (2001) Pathogenesis of Allergic Rhinitis. Journal of Allergy and Clinical Immunology, 99, S763-772. https://doi.org/10.1016/S0091-6749(97)70125-8

[16] Lambrecht, B.N. (2001) Allergen up Take and Presentation by Dendritic Cell. Current Opinion in Allergy and Clinical Immunology, 1, 51-59.

https://doi.org/10.1097/00130832-200102000-00010

[17] Maggi, L., Sanatrlasci, V., Liotta, F., et al. (2007) Demonstration of Circulating Allergen-Specific $\mathrm{CD} 4^{+} \mathrm{CD} 25^{\text {high }}$ Foxp $3^{+}$T-Regulatory Cells in Both Non-Atopic and Atopic Individuals. Journal of Allergy and Clinical Immunology, 120, 429-436. https://doi.org/10.1016/j.jaci.2007.05.002

[18] Kretschmer, K., Apostolou, I., Hawiger, D., Khazaie, K., Nussenzweig, M.C. and von Boehmer, H. (2005) Inducing and Expanding Regulatory T Cell Populations by Foreign Antigen. Nature Immunology, 6, 1219-1227. https://doi.org/10.1038/ni1265

[19] Zhang, L. and Zhao, Y. (2007) The Regulation of FoxP3 Expression in Regulatory $\mathrm{CD} 4{ }^{(+)} \mathrm{CD} 25^{(+)}$T Cells: Multiple Pathways on the Road. Journal of Cellular Physiology, 211, 590-597. https://doi.org/10.1002/jcp.21001

[20] Orihara, K., Narita, M., Tobe, T., Akasawa, A., Ohya, Y., Matsumoto, K., et al. (2007) Circulating FoxP3 ${ }^{+} \mathrm{CD} 4^{+}$Cell Numbers in Atopic Patients and Healthy Control Subjects. Journal of Allergy and Clinical Immunology, 120, 960-962. https://doi.org/10.1016/j.jaci.2007.05.036

[21] Nieminen, K., Valovirta, E. and Savolainen, J. (2010) Clinical Outcome and IL-17, IL-23, IL-27 and FoxP3 Expression in Peripheral Blood Mononuclear Cells of Pollen-Allergic Children during Sublingual Immunotherapy. Pediatric Allergy \& Immunology, 21, e174-e184. https://doi.org/10.1111/j.1399-3038.2009.00920.x

[22] Klatzman, D. and Abbas, A.K. (2015) The Promise of Low Dose Interleukin-2 Therapy for Autoimmune and Inflammatory Diseases. Natural Review Immunology, 15, 283-294. https://doi.org/10.1038/nri3823

[23] Zhang, L., Zhang, Y., Desrosiers, M., Wang, C., Zhao, Y. and Han, D. (2009) Genetic Association Study of FoxP3 Polymorphisms in Allergic Rhinitis in a Chinese Population. Human Immunology, 70, 930-934. https://doi.org/10.1016/j.humimm.2009.08.001

[24] Matsuaka, K.I., Korcth, J., Kim, H.T., Bascug, O.G., Kawano, Y., Murase, K., et al. (2013) Low Dose Inerleukin-2 Therapy Restores Regulatory T Cell Homeostasis in Patients with Chronic Graft versus Host Disease. Science Translational Medicine, 
56, $179 \mathrm{ra} 43$.

[25] Nieters, A., Linseisen, J. and Becker, N. (2004) Association of Polymorphisms in Th1, Th2 Cytokine Genes with Hayfever and Atopy in a Subsample of EPIC-Heidelberg. Clinical and Experimental Allergy, 34, 346-353.

[26] Nauri-Aria, K.T. and Durham, S.R. (2008) Regulatory T Cell and Allergic Disease. Inflammation \& Allergy-Drug Targets, 7, 237-252. https://doi.org/10.2174/187152808786848405

[27] Kundig, T.M. and Bachmann, M.F. (2010) Allergen Specific Immunotherapy: Regulatory T Cell or Allergen Specific IgG. Human Vaccines, 6, 673-675. https://doi.org/10.4161/hv.6.8.12007

[28] Hussein, P.Y., Zahran, F., AshourWahba, A., Ahmad, A.S., Ibrahiem, M.M., Shalaby, S.M., et al. (2010) Interleukin 10 Receptor Alpha Subunit (IL-10RA) Gene Polymorphism and IL-10 Serum Levels in Egyptian Atopic Patients. Journal of Investigational Allergology and Clinical Immunology, 20, 20-26.

[29] Nasiri, R., Mobarakeh, A.H., Movahedi, M., Farhadi, E., Ansaripour, A., Amirzargar, A.A., et al. (2015) Gene Polymorphisms of Interleukin-10 and Transforming Growth Factor Beta in Allergic Rhinitis. Allergologia et Immunopathologia, 44, 125-130. https://doi.org/10.1016/j.aller.2015.05.010

[30] Wachholz, P.A., Nouri-Aria, K.I., Wilson, D.R., et al. (2002) Grass Pollen Immunotherapy for Hay Fever Is Associated with Increases in Local Nasal But Not Peripheral Th1:1h2 Cytokine Ratios. Immunology, 105, 56-62. https://doi.org/10.1046/j.1365-2567.2002.01338.x

[31] Suh, K.S., Park, H.S., Nahm, D.H., et al. (2002) Role of IgG, IgA and IgE Antibodies in Nasal Polyp Tissue: Their Relationships with Eosinophilia Infiltration and Degranulation. Journal of Korean Medical Science, 17, 375-380. https://doi.org/10.3346/jkms.2002.17.3.375

[32] Yoshida, T., Usui, A., Kusumi, T., et al. (2005) A Quantitative Analysis of Cedar Pollen-Specific Immunoglobulin's in Nasal Lavage Sup Portal the Local Production of Specific IgE, Not of Specific IgG. Microbiology and Immunology, 49, 529-534. https://doi.org/10.1111/j.1348-0421.2005.tb03758.x

[33] Leatherman, B.D., Owen, S., Parker, M., et al. (2007) Sublingual Immunotherapy: Past Present Paradigm for the Future? A Review of the Literature. Otolaryngology-Head and Neck Surgery, 136, S1-S20. https://doi.org/10.1016/j.otohns.2006.11.057

[34] Kosmaczewska, A. (2014) Low-Dose Interleukin-2 Therapy: A Driver of an Imbalance between Immune Tolerance and Autoimmunity. International Journal of Molecular Sciences, 15, 18574-18592. https://doi.org/10.3390/ijms151018574 